\title{
Quality Management: An Index For Actual Practice And Managers Perception
}

Isaam Dawood, (E-mail: idawo@lakehead.ca), Lakehead University, Canada Bryan Poulin, Lakehead University, Canada

Bahram Dadgostar, Lakehead University, Canada

\begin{abstract}
The reviewed literature indicates that TQM is a potential source of competitive advantage. Although the efficacy of quality management has been studied in detail, the link between quality practices and managers' perceptions about TQM has received less attention. In this study, quality practices and managers' perceptions were investigated to advance a much-needed theoretical base, including underlying assumptions. Specifically, an instrument was developed and applied at 20 retail/service and 10 manufacturing companies in a distinct region in Canada, to measure managers' practices and perceptions on TQM dimensions. A quality index for each dimension allowed ranking and grouping of these dimensions. Additionally, case study research was conducted with a notable retailer of relevance to the region and Canada, and with a US manufacturing company noted for top-ranking on the top rated dimension-grouping, namely strategy, leadership and continuous improvement. The results suggest that studying managers' perceptions and their practices can contribute significantly to understanding the potential advantages of TQM.
\end{abstract}

\section{INTRODUCTION}

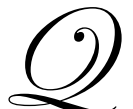

uality is elusive concept difficult to define; neither consultants nor business professionals agree on a universal definition. Part of the difficulty appears in expressing the philosophy and vision of quality in meaningful words and concepts. Thus we see quality gurus and scholars defining quality as 'fitness for use' (Juran, 1993), 'meeting all requirements' (Burge 1990), and 'totality of features and characteristics' (Evans, and Lindsay, 1996). Others offer a different tact. Rather than come up with a definition, these recommend looking to how low cost and quality are achieved, (Paskin, and Hart, 1996).

What all authors seem to agree about quality is that (1) it is a potential source of competitive advantage (Powell, 1995), (2) it has become a top management priority with the advent of globalization (Zairi and Dale, 2000), (3) it has been greatly influenced by the total quality management (TQM) movement that began in Japan (Carroll, 1995), (4) it is a management philosophy that emphasizes involvement of every employee to achieve customer satisfaction through continuous process improvement (Bank, 1992), (5) its implementation is accomplished through a set of practices that support the TQM philosophy (Dean and Bowen, 1994) and (6) it remains under the influence of TQM gurus Crosby Deming, and Juran and (Chow and Lui, 2001). Further, as Douglas and Judge (2001) point out, competitive advantage through TQM is based not on individual assets or practices that can be easily duplicated, but on the combination of a series of assets or "compound assets" (referred to as quality dimensions for the purpose of the study described in this paper).

\section{QUALITY FRAMEWORKS}

Frameworks for attaining competitive advantage through TQM include Crosby's (1979) 14-steps, Deming's $(1982,1986) 14$ points and Juran's (1986) trilogy. The review of the literature reveals other frameworks 
that are based on quality awards such as the Canadian Framework for Business Excellence, the U.S. Malcolm Baldrige Quality Award, the European Quality Award, the British Quality Award and Japan's Deming Prize.

In summary there are strong ties between the normative (award) frameworks and the empirically derived once (e.g. Saraph et a.l 1989; Flynn et al 1994; Tamimi, 1995; Ahire et al., 1996; Black and Porter, 1996; Zeitz et al., 1997) Figure 1 indicates the two types of frameworks and how both can be used together to determine the quality dimensions. Taken together, the studies indicate that the frameworks are similar to, or complement one another. All are essentially values-driven ideals and, as such, offer prescriptions to quality.

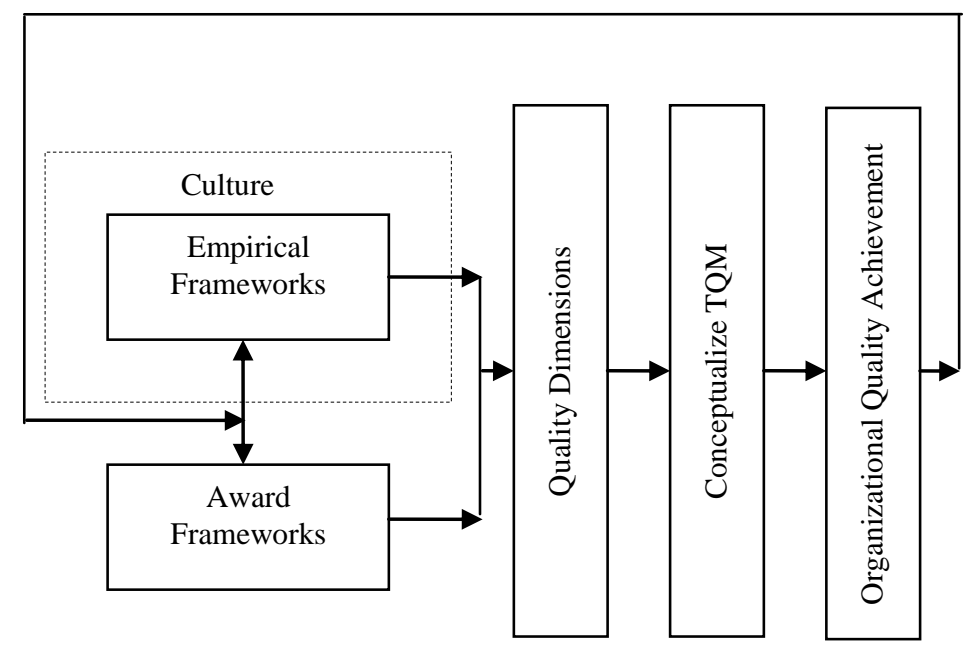

Figure 1: Review Of TQM Frameworks And Empirical Studies

\section{The Empirical Studies}

Generally speaking, most of the empirical studies have attempted to synthesize different TQM practices into a meaningful set of critical TQM dimensions. Rahman, and Sohal (2002) reviewed and classified TQM research in Australia between 1985 and 1999, and found that 65\% of the studies investigated TQM practices through identifying TQM dimensions. The others were more concerned with organizational performance and the existence of TQM practices.

However, it was not until recently that critical TQM dimensions were revealed in any coherent way (Chow, and Lui, 2001). For example, Saraph et al. (1989) synthesized the different TQM practices from the literature, first identifying the various components of TQM practices and then clustering the components to arrive at the eight dimensions of TQM. These results were then verified through tests of content validity, construct validity, and criterion-related validity and, they claimed, the dimensions allowed a reliable measure of TQM. Likewise, Tamimi (1995) attempted to simplify Deming's 14 points of TQM into a more structured form. From a total of 50 quality practices found in the literature, he also identified eight dimensions using exploratory factor analysis. Black and Porter (1995) modified the method of Saraph et al. by using the 1992 Malcolm Baldrige National Quality Award, and came up with 10 dimensions.

Kanji and Yui (1997) took a different approach and compared corporate cultures of Japanese companies and UK subsidiaries of Japanese companies that have implemented TQM. They defined the range in the characteristics of companies that have effectively implemented TQM in the two countries. Poza et al. (2001) added to this view by exploring the impact of cross-cultural differences on the facilitating effects of corporate culture on 
the implementation of TQM. They studied 133 manufacturing companies in the USA, Switzerland and South Africa, and concluded that the principles were robust but must be adapted to take into account ethnological and cultural differences. Table 1 shows a comparative list of critical dimensions of TQM, identified in the empirical studies over 1989 to 1998 decade, to illustrate types of studies and typical results.

Table 1: Critical Factors Of TQM Identified In Selected Empirical Studies 1989-1998

\begin{tabular}{|c|c|c|c|c|c|c|c|c|c|c|c|c|c|c|c|}
\hline $\begin{array}{l}\text { Quality } \\
\text { Dimensions }\end{array}$ & 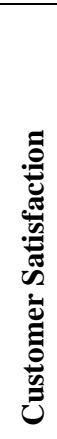 & 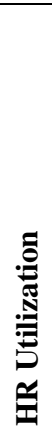 & 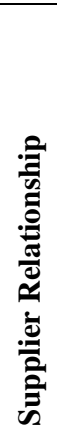 & 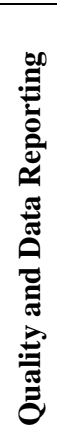 & 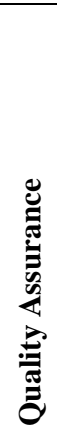 & 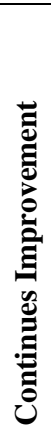 & 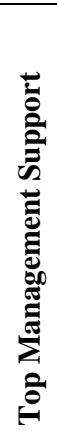 & 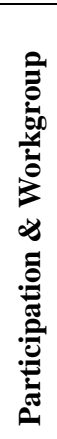 & 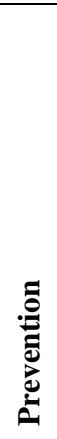 & 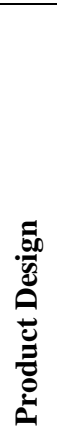 & $\frac{n}{8}$ & 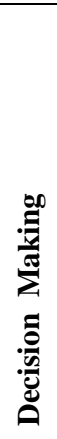 & 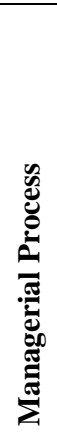 & 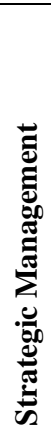 & 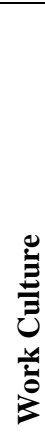 \\
\hline Ahire et al. (1996) & $\mathrm{X}$ & $\mathrm{X}$ & $\mathrm{X}$ & $\mathrm{X}$ & $\mathrm{X}$ & & $\mathrm{X}$ & $\mathrm{X}$ & & $\mathrm{X}$ & $\mathrm{X}$ & & & & $\mathrm{X}$ \\
\hline Anderson (1994) & $\mathrm{X}$ & & $\mathrm{X}$ & $\mathrm{X}$ & & $\mathrm{X}$ & $\mathrm{X}$ & $\mathrm{X}$ & & & & & & & \\
\hline Berry (1991) & $\mathrm{X}$ & $\mathrm{X}$ & & $\mathrm{X}$ & & $\mathrm{X}$ & $\mathrm{X}$ & $\mathrm{X}$ & & & $\mathrm{X}$ & & & & \\
\hline Black and Porter (1996) & $\mathrm{X}$ & $\mathrm{X}$ & $\mathrm{X}$ & $\mathrm{X}$ & $X$ & & $\mathrm{X}$ & & & & & & $\mathrm{X}$ & $\mathrm{X}$ & \\
\hline Brocka and Broka (1992) & $\mathrm{X}$ & $\mathrm{X}$ & $\mathrm{X}$ & $\mathrm{X}$ & $\mathrm{X}$ & & & & $\mathrm{X}$ & & & $\mathrm{X}$ & & & \\
\hline Carr and Littman (1990) & $\mathrm{X}$ & $\mathrm{X}$ & $X$ & $\mathrm{X}$ & $\mathrm{X}$ & & & & $\mathrm{X}$ & & & $\mathrm{X}$ & & & \\
\hline Chase and Aquilano (1992) & $\mathrm{X}$ & & $\mathrm{X}$ & & & $\mathrm{X}$ & & & $\mathrm{X}$ & & & & & & \\
\hline Cole (1995) & $\mathrm{X}$ & $\mathrm{X}$ & $\mathrm{X}$ & $\mathrm{X}$ & $\mathrm{X}$ & & & & $\mathrm{X}$ & & & $\mathrm{X}$ & & & \\
\hline Dale et al (1994) & $\mathrm{X}$ & & $\mathrm{X}$ & $\mathrm{X}$ & & & $\mathrm{X}$ & $\mathrm{X}$ & & $\mathrm{X}$ & $\mathrm{X}$ & & & & $\mathrm{X}$ \\
\hline Dean and Bowen (1994) & $X$ & $\mathrm{X}$ & $\mathrm{X}$ & $\mathrm{X}$ & $\mathrm{X}$ & $\mathrm{X}$ & $\mathrm{X}$ & $\mathrm{X}$ & & & $\mathrm{X}$ & & & & \\
\hline Evans and Lindsay (1996) & $\mathrm{X}$ & $\mathrm{X}$ & $\mathrm{X}$ & $\mathrm{X}$ & & $\mathrm{X}$ & $\mathrm{X}$ & & & & & & & $\mathrm{X}$ & \\
\hline Flood (1993) & $\mathrm{X}$ & & & & $\mathrm{X}$ & $\mathrm{X}$ & & & $\mathrm{X}$ & & & & & & \\
\hline Flynn (1992) & $\mathrm{X}$ & $\mathrm{X}$ & & & $\mathrm{X}$ & & $\mathrm{X}$ & & & $\mathrm{X}$ & $\mathrm{X}$ & & & & $\mathrm{X}$ \\
\hline Herzer and Ponder (1996) & & & & & $\mathrm{X}$ & $\mathrm{X}$ & & & & & $\mathrm{X}$ & & & & \\
\hline Jablonski (1991) & $\mathrm{X}$ & $\mathrm{X}$ & $\mathrm{X}$ & $\mathrm{X}$ & $\mathrm{X}$ & & & & $\mathrm{X}$ & & & $\mathrm{X}$ & & & \\
\hline Knotts and Tomhin (1994) & $\mathrm{X}$ & $\mathrm{X}$ & $\mathrm{X}$ & $\mathrm{X}$ & & & & & & & & & $\mathrm{X}$ & & \\
\hline Martin (1993) & $\mathrm{X}$ & $\mathrm{X}$ & & $\mathrm{X}$ & & $\mathrm{X}$ & $\mathrm{X}$ & & & & & & $\mathrm{X}$ & & \\
\hline Martinich (1997) & $\mathrm{X}$ & & $\mathrm{X}$ & $\mathrm{X}$ & $\mathrm{X}$ & $\mathrm{X}$ & & $\mathrm{X}$ & $\mathrm{X}$ & $\mathrm{X}$ & $\mathrm{X}$ & & & & $\mathrm{X}$ \\
\hline McGowan (1995) & $\mathrm{X}$ & $\mathrm{X}$ & & & & $\mathrm{X}$ & & $\mathrm{X}$ & & $\mathrm{X}$ & & & & & \\
\hline Raghunathan et al. (1993) & $\mathrm{X}$ & $\mathrm{X}$ & $\mathrm{X}$ & $\mathrm{X}$ & $\mathrm{X}$ & & $\mathrm{X}$ & $\mathrm{X}$ & & & & & & & \\
\hline Saraph et al. (1989) & $X$ & $\mathrm{X}$ & $X$ & $\mathrm{X}$ & $\mathrm{X}$ & & $\mathrm{X}$ & & & $\mathrm{X}$ & $\mathrm{X}$ & & & & \\
\hline Solis et al. (1998) & $\mathrm{X}$ & $\mathrm{X}$ & $\mathrm{X}$ & $\mathrm{X}$ & $\mathrm{X}$ & & $\mathrm{X}$ & & & $\mathrm{X}$ & & & & & \\
\hline Tenner and Detaro (1992) & $\mathrm{X}$ & $\mathrm{X}$ & $\mathrm{X}$ & $\mathrm{X}$ & $\mathrm{X}$ & & & & $\mathrm{X}$ & & & $\mathrm{X}$ & & & \\
\hline Vendermbse (1996) & $\mathrm{X}$ & $\mathrm{X}$ & & & & $\mathrm{X}$ & & $\mathrm{X}$ & & & & $\mathrm{X}$ & & & \\
\hline Zeitz et al. (1997) & $\mathrm{X}$ & & $\mathrm{X}$ & & & $\mathrm{X}$ & & & & & $\mathrm{X}$ & & $\mathrm{X}$ & & \\
\hline & 24 & 18 & 18 & 18 & 15 & 12 & 12 & 9 & 8 & 7 & 7 & 6 & 4 & 4 & 4 \\
\hline
\end{tabular}

Garvin (1988) suggested that the dimensions of quality affect quality practices. Thus Zhang (2001) argued that quality must be viewed from different perspectives to address diverse quality dimensions effectively, since managers' quality perspectives expand or limit their practices. The theoretical framework of the Zhang (2000) study was based on the assumption that the actual practices of quality are clearly associated with their perspectives of quality. Hence the successful firms are more associated with an integrated implementation of quality concept (i.e. integrated quality dimensions, perspectives, and practices). 
In summary, the reviewed literature indicates that TQM is a potential source of competitive advantage. Although quality management practices have been studied in detail, the link between quality practices, and managers' perceptions about TQM has been given less attention.

\section{RESEARCH METHODS}

Though most empirical survey-based studies contained in the general frameworks propagated by the TQM gurus, the empirical survey studies on TQM are supposed by many to offer higher validity than the nonempirical TQM studies (Motwani, 2001). However, our contention is that quantitative survey research and qualitative case research can both be convincing and even more so when combined (Hofstede et al., 1990). While the quantitative results of the surveys can point to priorities, and help with the model building, the qualitative caseresults often offer the most compelling evidence for explaining results, both quantitative and qualitative. This is consistent with a few of the more credible research methods scholars, both theoretical (e.g., Patton 1990) and applied (Yin, 1989). Such suggest that mixed methods help build, test and refine a theoretical base.

The objectives of the research in this paper are to study managers' perceptions and practices with TQM and so contribute to the understanding of TQM in a more meaningful and useful way. The idea is to capture the best of TQM. This may be accomplished by using the managerial perceptions of TQM and their practices, measuring the importance of each of TQM dimensions, and ranking and grouping these dimensions into an overall, integrated framework. Thus the objectives of this paper may be more specifically expressed this way: to develop a method to measure TQM dimensions, o formulate an integrated framework of TQM dimensions, and to consider the implications of TQM dimensions as practiced by a range of firms.

To satisfy the first objective, a survey questionnaire was developed, based on factors considered most important in the TQM literature, to measure selected information about the sampled organizations including both managers' practices, and their perceptions of TQM dimensions. The second objective looked at the pattern apparent in the rank ordering of the TQM dimensions. The third objective required looking for explanation of the results by looking to two well-known and 'model' companies that would most graphically illustrate the differences between what was said to be important and what was practiced - the failed Eaton's company (retail chain store) in Canada and the successful Nucor corporation (steel manufacturing) in the U.S.

The measure of each quality dimension in the survey was developed using a seven-point Likert Scale. This section asked respondents to indicate the actual level of each quality factor, as they practice it in their organizations, and their perception of the importance of each quality factor regardless of the actual practice. The target respondents were 39 senior managers of manufacturing and service organizations who were responsible for quality programs from organizations working in Northwest Ontario. Simple random sample procedures were applied to select these target managers. The attributes of TQM, identified from review of the literature, were generally consistent with the eleven factors forming criteria of The Canadian Framework for Business Excellence Award. These eleven dimensions, in no particular order are:

1. Customer Satisfaction

2. Supplier Relationship

3. Human Resource Utilization

4. Participation And Team-Work

5. Process Development

6. Quality Assurance

7. Strategic Planning Process

8. Quality Culture,

9. Data Analysis,

10. Continues Improvement

11. Leadership 


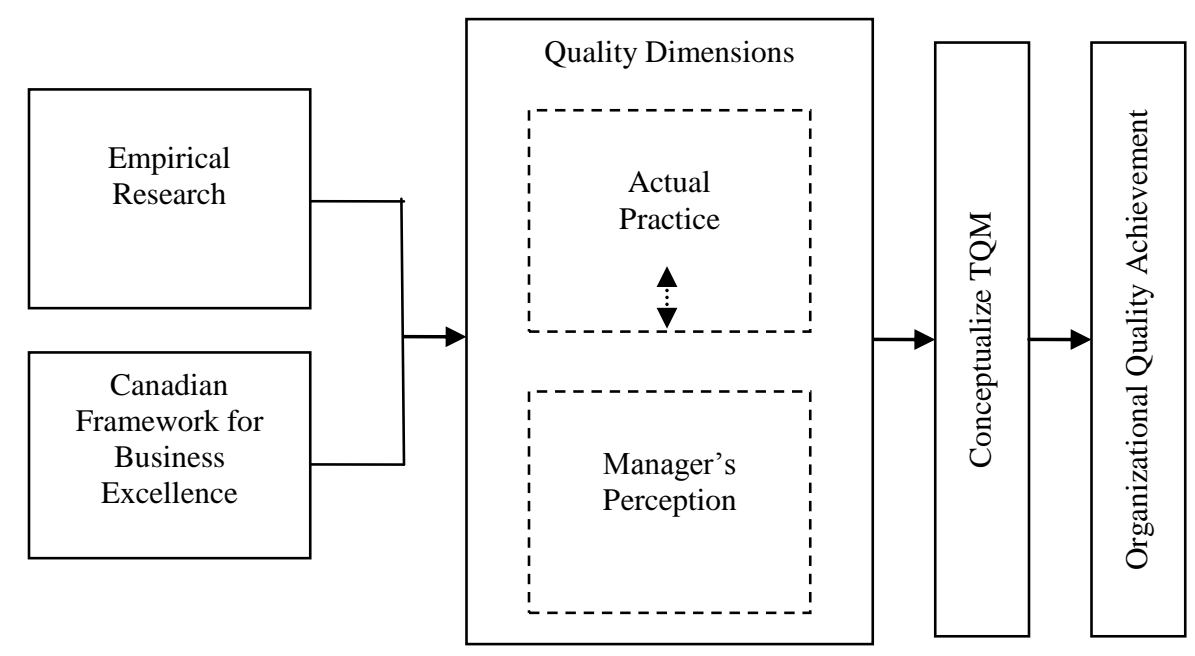

Figure 2: Framework Of The Study

The validity of the measurement was based on the review of the literature, and by examining the internal consistency of a set of measurement items. The measurement refers to the degree to which attributes in the set are homogeneous. Internal consistency was estimated using a Cronbach's alpha reliability coefficient. Table 2 reports the value of alpha for the 11 dimensions. It shows that the reliability coefficients ranged from 0.717 to 0.962 . It indicates that the scales developed are judged to be reliable.

Table 2: The Reliability Of Empirical Measurement (Alpha)

\begin{tabular}{|c|c|c|c|c|c|c|c|c|c|c|c|c|}
\hline & \multicolumn{11}{|c|}{ Dimensions } \\
\hline & & 1 & 2 & 3 & 4 & 5 & 6 & 7 & 8 & 9 & 10 & 11 \\
\hline \multirow{2}{*}{ 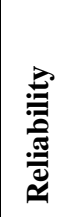 } & $\begin{array}{l}\text { Actual } \\
\text { Practice }\end{array}$ & .860 & .773 & .804 & .896 & .951 & .744 & .964 & .883 & .864 & .863 & .962 \\
\hline & Perception & .744 & .811 & .815 & .859 & .884 & .735 & .989 & .717 & .741 & .765 & .907 \\
\hline
\end{tabular}

The second objective of this paper is to formulate an integrated framework of TQM dimensions by calculating an index which reflects the rank of each dimension in the TQM adoption. The following multiattribute attitude model has been employed to calculate the index. This linear compensatory model is stated (Bass and Wilkie, 1973) as:

$A_{j k}=\sum_{i=1}^{n} I_{i k} B_{i j k} \quad$ Where:

$\mathrm{i}=$ quality attribute

$\mathrm{j}=$ quality dimension

$\mathrm{k}=$ manager or respondent 
Such that:

$A_{j k} \quad=$ manager $k$ 's rating for dimension $\mathrm{j}$

$I_{i k} \quad=$ the actual practice weight of attribute $i$ by manager $k$

$B_{i j k} \quad=$ manager $k$ 's perception of the importance of attribute $i$ dimension $j$.

$I_{i k} B_{i j k}=$ content variable or component of the index

Each dimension has two values. The first is the actual practice. The second is managers' perception of the impermanence of the dimension regardless of the actual practice.

The organizations included in the sample were classified into two groups, services and manufacturing. Thirty (30) organizations or $67 \%$ belong to the services group, which includes insurance, banking, communication, and construction. Nine (9) organizations or $23 \%$ belong to the manufacturing group. Fig. 3 shows that the sampled organizations arranged into four groups according to the total number of employees. The smallest firm had 21 employees, the largest 1600 employees. The average was 471 employees.

Fig. 4 shows that the sampled organizations arranged into four groups according to the number of years in operation. The youngest organization is 6 years old, while the oldest one is 109 years old. The average is 75 years.

To assess whether or not there were significant differences between the organizational type (services, and manufacturing) in the total number of employees, and the number of years in operations, the Kruskal-Wallis test was used. The Kruskal-Wallis test is a nonparametric test. It is applicable because the variable in question does not have a continuous distribution, and the sample is independent. The results have shown no significant differences between organizational type, in number of employees $\mathrm{F}=2.262, \mathrm{P}=1.33$, and in years in operation $\mathrm{F}=0.817, \mathrm{P}=0.366$.

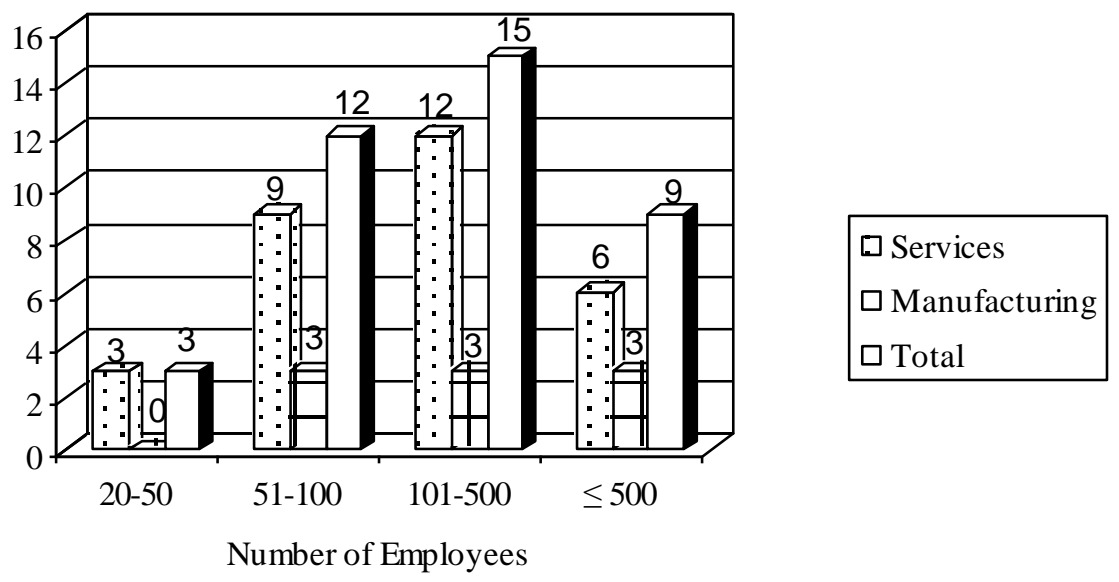

Figure 3: Subjects Of The Study 


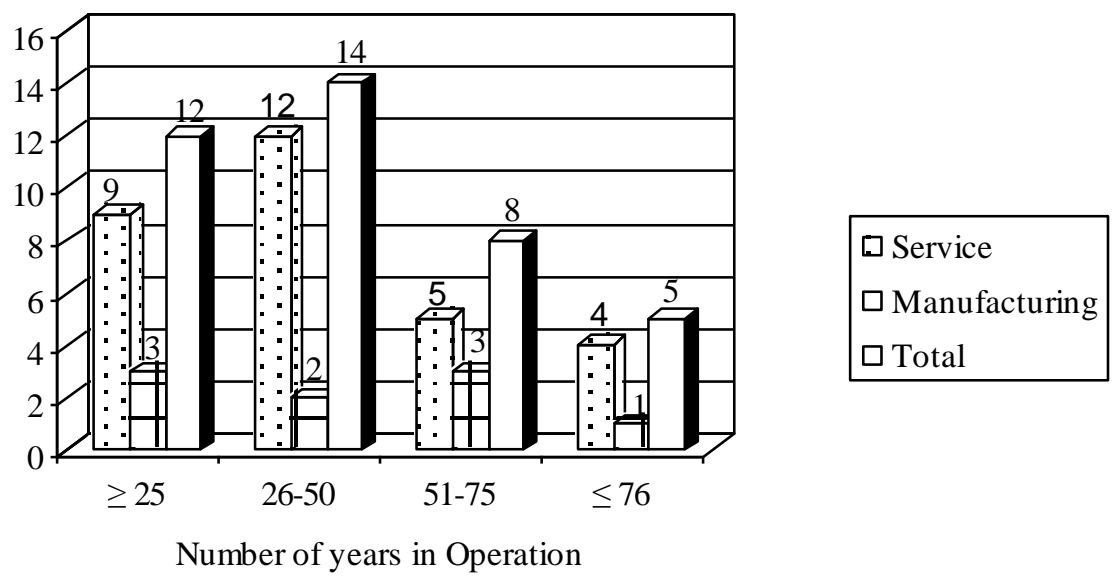

Figure 4: Number Of Years In Operations

\section{EMPIRICAL RESULTS}

\section{Total Quality Management Dimensions’ Index}

A multi-attribute attitude model was employed to calculate the index for each TQM dimension. The mean indexes for all quality dimensions in the study are presented in Table 3. This table shows that strategic planning process dimension, leadership dimension, and continuous improvement dimension have the highest quality index means. On one hand, the results confirm some of the TQM dimensions. On the other hand, some TQM dimensions appear as not so important, i.e. supplier relationship, process development and human resource utilization. Here the low quality index means may be partly explained by the high means on the leadership dimension. This is because leadership requires followers, and how followers are treated is more a leadership concern than 'human resource utilization', a term that might even offend leaders. In fact, there are some leadership scholars who would argue that treating people simply as resources implies disrespect and is contrary to leadership (e.g. Deming, 1984; Boxall, 1994).

The criteria of Canada Award for Excellence also emphasize the requirement for overall business success. Thus, more points are allocated to leadership dimension, and strategic planning dimension, than supplier relationship dimension. Based on follow-up interviews, two managers mentioned that the quality award framework is the best thing to happen to quality in organizations. Yet, what managers say is not always reflective of what they do and, even if there is the intention for managers to be consistent, there are always gaps between what is done and what might be done. This leads us to examine in more detail what happened in two firms that represent a range of management opinion and firm action and results along the dimensions identified in the study so far.

\section{Case Analysis}

We began with Eaton's in 1999 when this former icon of Canadian retail was poised to disappear from the Canadian landscape (McQueen, 1998). No Canadian company had done more to transform a country than Eaton's. We then went on to study Nucor Corporation, now well-known, thanks in major part to Collins' (2001) Good to Great book that identified it as one of the two top performing firms (Circuit City being the other) among U.S. Fortune 500 companies. Nucor is presented first, followed by Eaton's, both in terms of the 11 factors of Table 3 . 
Table 3: Mean Index For TQM Dimensions

\begin{tabular}{|l|c|c|}
\hline \multirow{2}{*}{\multicolumn{1}{|c|}{ Quality Dimension }} & \multicolumn{2}{c|}{$\begin{array}{c}\text { Quality } \\
\text { Index }\end{array}$} \\
\cline { 2 - 3 } & Mean & 1 \\
\hline Strategic Planning Process & 5.44 & 2 \\
\hline Leadership & 5.40 & 3 \\
\hline Continuous Improvement & 5.38 & 4 \\
\hline Quality Assurance & 5.22 & 5 \\
\hline Customer Satisfaction & 5.18 & 6 \\
\hline Data Analysis & 5.09 & 7 \\
\hline Participation and Team-Work & 4.89 & 8 \\
\hline Quality Culture & 4.88 & 9 \\
\hline Human Resource Utilization & 4.85 & 10 \\
\hline Process Development & 3.97 & \\
\hline Supplier Relationship & 3.00 & \\
\hline
\end{tabular}

\section{NUCOR CORPORATION}

In the spring of 2003, we decided to verify what Collins (2001) had said about Nucor and we conducted a qualitative study that sought to capture what had happened to make this company such as model case between 1965 and 1995, the period studied by Collins. The Nucor study was a reflective case in that people were asked to recall what had occurred in years prior to 1995, in 2004 and 2005. The people interviewed generally met the criteria of Hofstede et al. (1990) for capturing the culture of the company. This meant interviewing a top manager of Nucor, and his/her secretary, an old-timer, a newcomer and an employee representative. Interestingly, besides detailing the 11 TQM dimensions, the study also uncovered an integrating principle --- fairness --- that seemed to guide all other factors, and the firm and its managers and employees, to the highest levels. This fairness principle will be made more explicit and will be described in more detail in the concluding section. Here is a summary explanation of the 11 dimensions, from the perspective of Nucor Corporation, starting with the top ranked one, strategic planning.

Strategic Planning: Nuclear Corporation of America, later renamed Nucor Corporation, was a hodge-podge of unrelated businesses. Starting in 1965, the new top managers Ken Iverson (CEO) and Sam Siegel (CFO) transformed the company by focusing on what it could do best: manufacture steel products. It became the low-cost producer of steel in the U.S. by applying, in Sam Siegel's (2004) words, "basic management principles". Following a textbook approach to strategic planning, and including fairness in all dealing, Nucor built 'state-of the art' ministeel mills, linked pay to performance at all levels and became the most productive steel maker in the U.S. and the world, and the highest paying.

Leadership: Nucor top managers Iverson (CEO) and Siegel (CFO) viewed themselves as simply employees who had an extra responsibility of looking after the entire company, and thus leading by example, developing a structure that was flat (only 5 levels between CEO and front line workers) and taking pride in what they did, together, with other workers. The result: 'egalitarian meritocracy' and fair treatment of workers, suppliers, communities and shareholders, all sharing gains during good times, and 'pains' during the few bad times (due to downturns in the business cycle).

Continuous Improvement: Nucor encouraged, and rewarded workers in groups for continually looking for ways to improve the system. For example, one supervisor worked with his team to reduce the number of hours to tear down and rebuild a key part of the steel mill from the equipment manufacturer's recommended time of 36 hours (industry norm) to 24 hours and, finally, to 12 hours. Another example of continuing improvement was with an administrative group that computerized the billing system so all customers could be charged the same unit rate, unlike other steel companies that practiced differential unit pricing that depended on volumes ordered. 
Quality Assurance: Nucor ensured quality in steel-making, fabrication and delivery by having its own testing and quality assurance facilities and by making corrections when things went wrong, in cases where mistakes or errors were found years or even decades later. One example was when pollution had occurred with a former subsidiary company in the 1950s that had manufactured ceramics. This well before Iverson and Siegel's time and well after the subsidiary had been sold off, in keeping with the new focus on steel making and steel fabrication. Nucor was the only company to pay for the environmental damages, voluntarily without litigation, ensuring that the company stood for quality in a broad and not narrow sense.

Customer Satisfaction: Nucor treated customers like all people that were associated with the firm, with dignity. That meant offering customers the highest quality products at lowest possible price, on time and just in the quantities needed, on terms that were fair for all customers. The result of this, including same unit price to all customers, large and small, was high customer satisfaction for products that would 'normally' be considered undifferentiated.

Data Analysis: Nucor analyzed key production, cost and sales data from each facility on a daily, weekly, monthly and annual basis from its small but highly efficient head office in Charlotte, North Carolina.

Participation and Teamwork: Employees were organized into teams and larger groups and goals were set and developed so that each team knew the goals, worked to meet and exceed these, and then rewarded accordingly in terms of teams, larger groups and company as a whole.

Quality Culture: Nucor emphasized a total quality culture that resulted in stakeholders being affected in ways that made each and all better for this.

Human Resource Utilization: Goal-oriented employees of Nucor became the most productive, profitable and loyal workforce in the steel industry.

Process Development: Nucor kept developing processes to make Nucor more productive.

Supplier Relationship: Suppliers were engaged to help make Nucor more efficient.

In summary, Nucor Corporation from 1965 to 1995, under what might be termed the 'strategic leadership' of Iverson and Siegel, oversaw the transformation of a disjointed and directionless firm into what might be termed a company that reflected 'total quality management' in all 11 dimensions. This could similarly describe Eaton's of Canada, but only during the first 40 years under the direction of its founder. Timothy Eaton.

\section{THE T. EATON COMPANY OR EATON'S}

By the summer of 1999, the T. Eaton Company or simply Eaton's, as it was known to Canadians, was poised for a second round of bankruptcy protection, having failed to engage customers and having defaulted on payment to its suppliers. This was the company that had introduced quality and value and almost single-handedly led better working conditions at the turn of the $20^{\text {th }}$ century. We decided to investigate what had happened to Eaton's. Like at Nucor, we again were able to summarize the results in terms of the 11 dimensions, starting with strategic planning. Unlike at Nucor, we considered the later fall or Eaton's, as well as the earlier transformation and rise that had occurred.

Strategic Planning: Eaton's began in 1869 following a strategy of differentiation on affordable prices, selection of goods, a no-hassle return policy and service that was unmatched in Canada (Santink, 1990). The strategy carried the company until the 1950s, by which time its chain of department stores held an incredible $58 \%$ of all retail trade (McQueen, 1998).

Leadership: Eaton's can said to have had only one leader and that was Timothy Eaton. T. Eaton pioneered retailing in Canada and benchmarked his company against the best in the world. T. Eaton shortened the work-week from six and a half days, 10 to 12 hours a day, to five and an half days, 8 hours a day, setting the standard for the work week 
in Canada. He also offered shareholding to key employees, an outcome of his personal and religious beliefs in equal opportunity for people. After the founder, T. Eaton passed away in 1907, the store went through into a series of managers who saw, as their primary responsibility, 'carrying on' the successes of the founder.

Continuous Improvement: The store really only continuously improved during founder T. Eaton's time and later managers actually wound down earlier innovations, including employee share-ownership.

Quality Assurance: Assurance of having the right quality of goods, supplied in the right way, also drifted downwards after the founder's time.

Customer Satisfaction: Customers became increasingly uncaring about Eaton's as it became increasing unconcerned with their welfare.

Data Analysis: Data was not collected to see how the rot had set in.

Participation and Team-Work: Teamwork suffered although employees remained surprising loyal as they looked back on better days of the past.

Quality Culture: The total quality culture of former years weakened over the 90 years since the founder's death though again it lasted a very long time.

Human Resource Utilization: Goal-oriented employees continued to do their best though people were not engaged as in former years.

Process Development: Beyond the initial years, little attempt was made at process.

Supplier Relationship: Suppliers were treated as factor inputs by the1990s.

\section{CONCLUSIONS AND DIRECTIONS FOR FUTURE RESEARCH}

The current quantitative and qualitative study provided a more comprehensive method to study TQM as it applied in the firms examined. The literature allowed formulation of an initial framework of TQM dimensions. This was later assessed by integrating managerial practices and perceptions to calculate an index to measure TQM dimensions, and rate them based on their importance in adopting TQM. A more in-depth understanding of the specific challenges in implementing TQM arose from the quality index and knowing what dimensions were most important, confirmed and illustrated by the qualitative study that allowed for detailed explanation.

Empirical quantitative results of this study indicated that the strategic planning process dimension, leadership dimension, and continuous improvement dimension have the highest quality index means. The closeness in ratings along these dimensions reflects that consistency may be the over-riding consideration for overall business success. Empirical qualitative results of just two cases, Nucor the model case, and Eaton's both a model (1869 to 1907) and contrary case (1908-1999) indicate the power of mixed methods to determine what are important factors and how these are linked.

The study further suggests that in order to understand TQM, at least as practiced in Canada and the U.S., future research should be carried out with a larger sample size, both in terms of cases and companies surveyed. Of course, ideally, the cases studied would be drawn from the same set as the companies surveyed. The exploratory nature of the present study meant that these requirements had to be waived since it was considered unlikely a model or contrary case would be in the first group: it was simply too small. That said, we suspect that the results for this larger sample would confirm most it not all of the results of this study because our results are, in large measure, similar to other studies of other cases and surveys, including our own. Uncovering of the 'fairness principle' suggests that a fairness perspective together with 'quality' drove the 11 quality factors, at Eaton's for 40 years 
(1869-1906) and Nucor for 30 years (1965-1995). If this proves to be the more general case, we see three major implications as follows:

(1) The top rated factors --- strategy, leadership and continuous improvement may be dimensions that can be grouped on the basis being complementary;

(2) Other factors may also be similarly grouped, either for similar or different reasons; and

(3) Together the groupings might lead to a 'meta model' of management that helps explain the importance of quality and predicts the future direction of management theory and practice, dealing as it might, in terms satisfaction from an enlightened and multiple stakeholder-viewpoint.

In short, we view this as an important beginning to mixed-methods research that is able to deal with multiple factors and uncover such integrating notions such as fairness, a notion that has the power to integrate seeming tradeoffs. This seems compatible with TQM, for after all, viewing quality and cost as complementary was 'invented' by it.

\section{REFERENCES}

1. Ahire, S., Golhar, D. and Waller, M. (1996). Development and Validation of TQM Implementation Constructs. Decision Sciences 27, 1, 23-56.

2. Badri, M., Davis, D., and Davis, D. (1995). A Study of Measuring the Critical Factors of Quality Management. International Journal of Quality and Reliability. 12, 2, 36-53.

3. $\quad$ Bank, J. (1992). The Essence of Total Quality Management. Hemel Hempstead: Prentice-Hall.

4. Black, S. and Porter, L. (1996). Identification of the Critical Factors of TQM. Decision Sciences. 27, 1, 121.

5. Black, S., and Porter, L. (1995). An Empirical Model for Total Quality Management, Total Quality Management. 6, 2, 149-165.

6. Boxall, P. Ppacing HR Strategy at the Heart of Business Success, Personnel Management, July, 32-35.

7. Burge, B. Producing a Quality Product. Journal of Systems Management. November, 7.

8. Carroll, J. (1995). The application of Total Quality Management to Software Development. Information Technology and People. 8, 4, 35-47.

9. Chow, W., and Lui, K. (2001). Discriminating Factors of Information Systems Function Performance in Hong Kong firms Practicing TQM. International Journal of Operations and Production Management. 21, 5/6, 749-771.

10. Collins, J. 2001. Good to Great, New York: Harper Collins.

11. Crosby, P. (1979). Quality is Free. New York: McGraw-Hill.

12. Dean, J., and Bowen, D. (1994). Management Theory and Total Quality: Improving Research and Practice through Theory Development. Academy of Management Review. 19, 392-418.

13. Deming, W. (1982). Quality, Productivity, and Competitive Position. Cambridge, MA: MIT Center for Advanced Engineering Study.

14. Deming, W. (1986). Out of the Crisis. Cambridge: Cambridge University Press.

15. Dewhurst, F., Lorente, A., and Dale, B. (1999). Total Quality Management and Information Technologies: an Exploration of the Issues. International Journal of Quality and Reliability Management. 16, 4, 392-405.

16. Douglas, T., and Judge, W. (2001). Total Quality Management Implementation and Competitive Advantage: The Role of Structural Control and Exploration. Academy of Management Journal. 44, 1, $157-$ 169.

17. Eaton, F. (1999) Interview with Mr. Fred Eaton, O.C., retired CEO of the T. Eaton Company, August 5.

18. Evans J., and Lindsay, W. (3ed. Ed.), (1996). The Management and Control of Quality. USA: West Publishing Company.

19. Feigenbaum, A. (3ed Ed.), (1991). Total Quality Control. New York: McGraw-Hill.

20. Flynnet, B., Schoeder, R. and Sakibaba, S. (1994). A Framework for Quality Management Research and Associated Measurement Instrument. Journal of Operations Management. 11, 339-366.

21. Garvin, D. (1988). Management Quality. New York: The Free Press. 
22. Hofstede G., Nevijen B, Ohayo D., and Sonders G. (1990). Measuring Organizational Cultures: A Qualitative and Quantitative Study Across Twenty Cases, Administrative Science Quarterly, Vol 16, 321338.

23. Juarn, M. (1986). The Quality Trilogy. Quality Progress. 9, 8, 19-24

24. Juran, M. (1989). Juran on Leadership for Quality: An Executive Handbook. New York: The Free Press.

25. Juran, M. (1993). The Last Word Tour Conference Mahwah, New Jersey. 16 August.

26. McQueen, R. (1998). The Eaton's: The rise and fall of Canada's royal family. Toronto, Canada: Stoddart.

27. Motwani, J. (2001), Measuring Critical Factors of TQM. Measuring Business Excellence, 5, 2, 27-30.

28. Patton, M Q. (1990) Qualitative Evaluation and Research Methods, Sage Publications, Newbury Park, California.

29. Peskin, M., and Hart, J. (1996). Measuring the Quality of Computer Systems Development. Benchmarking for Quality Management and Technology. 3, 2, 68-84.

30. Powell, T. (1995). Total Quality Management as a competitive advantage: A Review and Empirical Study. Strategic Management Journal. 16, 15-37.

31. Poza, A., Nystrom, H., and Wiebe, H. (2001). A Cross-cultural Study of the Differing Effects of Corporate Culture on TQM in three Countries. International Journal of Quality and Reliability Management. 18, 7 , 744-761.

32. Rahman, S., and Sohal, A. (2002). A Review and Classification of Total Quality Management Research in Australia and an Agenda for Future Research. International Journal of Quality and Reliability Management. 19, 1, 46-66.

33. Santink, J. L. (1990). Timothy Eaton and the rise of his department store. Toronto, Canada: University of Toronto Press.

34. Saraph, J., Benson, P., and Schroeder, R. (1989). An Instrument for Measuring the Critical Factors of Quality Management. Decision Sciences. 20, 810-829.

35. Siegel, S. 2004. Interviews with Mr. Sam Siegel, retired vice-chairman and CFO, Nucor Corporation 21 and 23 July.

36. Tamimi, N. (1995). An empirical Investigation of Critical TQM Factors Using Exploratory Factor Analysis. International Journal of Production Research. 33, 11, 3041-3051.

37. Wu, H., (1996). Development of a self-evaluation stem for Total Quality Management Using the Baldrige Criteria. Dissertation, University of Missouri-Rolla, MO.

38. Wu, Y., Wiebe, H., and Politi, J. (1997). Self -assessment of Total Quality Management Programs. Engineering Management Journal. 9, 1, 25-31.

39. Yin, R.K. (1989) Case Study Research: Design and Methods, Sage Publications. Newbury Park, California.

40. Zairi, Thiagaragan, and Dale, B. G. (2000). A Proposed Model of TQM Implementation based on an Empirical Study of Malaysian Industry. International Journal of Quality and Reliability Management. 18, 3, 289-306.

41. Zeitz, G., Johannesson, R. and Ritchie, J. E. Jr. (1997). An Employee Survey Measuring Total Quality Management Practices and Culture. Group and Organization Management. 22, 4, 414-444.

42. Zhang, Q., (2001). Quality Dimensions: Perspectives and Practices A mapping Analysis. International Journal of Quality and Reliability Management. 18, 7, 708-721. 